\title{
RECEÇÃO MEDIÁTICA E HISTÓRIA ORAL Operárias da Covilhã no Estado Novo
}

\author{
José Ricardo Carvalheiro \\ LabCom - Universidade da Beira Interior, Portugal \\ Diana Gonçalves Tomás \\ LabCom - Universidade da Beira Interior, Portugal
}

\begin{abstract}
Resumo: O período do Estado Novo (1933-1974), caracterizado por um sistema social fortemente patriarcal, assistiu também à entrada de novos meios de experiência simbólica, a rádio e da televisão, na vida das mulheres. Recorrendo à história oral, este artigo procura pistas acerca da forma como decorreu essa implantação da receção mediática entre o operariado têxtil da Covilhã, recorrendo a memórias femininas sobre a articulação dos media com os espaços domésticos e os lugares públicos, e sobre os modos como as interações sociais se foram acomodando ou transformando nesse processo. O texto propõe um quadro teórico para analisar a história da receção numa perspetiva de género, partindo dos conceitos de receção mediática, hegemonia e dominação para explorar dados empíricos provenientes de entrevistas biográficas.
\end{abstract}

Palavras-chave: História oral; receção mediática; mulheres; Estado Novo

Em Portugal, usar história oral para abordar memórias femininas de meados do século XX é suscitar a rememoração de contextos fortemente patriarcais. Em certas evocações, as próprias mulheres que os viveram reconhecem-nos hoje como de grande assimetria entre géneros. Noutras o carácter assimétrico das relações entre masculino e feminino mantém-se naturalizado. Por isso, conceitos como hegemonia, dominação e ordem simbólica constituem instrumentos teóricos para examinar as memórias de mulheres acerca das suas experiências biográficas, e são esses que propomos para analisar o contexto entre as décadas de 1930 e 1960.

Durante este período, os media eletrónicos foram penetrando o quotidiano e a receção mediática deve ser abordada dentro de experiências biográficas mais vastas, num contexto em que os media foram passando de artefactos marginais a tecnologias emergentes. Procuramos, especialmente, compreender a coincidência histórica que articulou um sistema patriarcal com novas fontes de experiência social e simbólica constituídas pela rádio e pela televisão, com o objetivo de averiguar se a adoção dos media eletrónicos, em espaços domésticos e públicos, foi acompanhada por transformações nos papéis de género, ou se os novos media foram acomodados num 
quotidiano hegemónico sem que as relações de subordinação feminina tenham sofrido alterações. À coincidência histórica de um regime autoritário e patriarcal com a gradual radicação de novas mediações simbólicas no quotidiano feminino, propomo-nos observá-la especificamente no interior de um contexto operário como era a Covilhã de meados do século XX.

Neste texto, recorremos exploratoriamente a entrevistas biográficas para articular uma teia de memórias nas quais os media são uma parcela, frequentemente fragmentária, e cuja conceptualização desejamos, antes do mais, ponderar.

\section{A história da receção e as suas dimensões}

Nem sempre os estudos históricos sobre audiências recorrem a conceitos precisos acerca do que constitui a atividade de receção, surgindo por vezes esta noção indiscriminada a par da de usos e os dois conceitos como tendo sentidos intercambiáveis (Jensen, 1993; Podber, 2007).

Julgamos útil distinguir várias dimensões dentro de um conceito lato de receção. Embora essa distinção não passe de uma ferramenta analítica que se dispõe a separar conceptualmente aspetos que coexistem na realidade, propomos discriminar as noções de usos dos media e de apropriação mediada de formas simbólicas.

Para que os sujeitos se tornem audiência, há sempre alguma forma de ação em que eles têm de se envolver, uma forma de usar, e é aí que o conceito de usos tem relevância. A ideia de que usar os media implica ações concretas ajuda a encarar as práticas como específicas de certos contextos históricos. Aquilo a que nos referimos com este conceito é aos modos e às circunstâncias em que as pessoas escutam rádio ou veem televisão. Nesta base, é possível mapear historicamente a atividade das várias audiências em termos de usos individuais, contextos familiares ou reuniões coletivas, assim como em termos de espaços domésticos ou espaços públicos, e ainda considerar o conjunto de interações sociais em que os sujeitos se envolvem enquanto usam os media.

O conceito de receção, por sua vez, tomou um sentido específico dentro da tradição propriamente chamada de "estudos de receção", onde o aspeto considerado fundamental na atividade das audiências é o processo de interpretação dos textos mediáticos. Esta atividade interpretativa não implica apenas dar sentido aos símbolos, mas envolve também sucessivos momentos de autorreflexividade por parte da pessoa que os interpreta, ou seja, trata-se uma atividade de apropriação simbólica e não de mera receção (Thompson, 1995). Em entrevistas biográficas surgem interpretações de textos mediáticos realizadas várias décadas após a sua receção, 'leituras' que não 
podem deixar de ser processos reinterpretativos em que intervêm dados biográficos e simbólicos que são posteriores à receção: experiências vividas, reconfigurações identitárias, novas subjetividades e intertextualidades que os indivíduos entretanto acumularam vêm reconfigurar as interpretações de um texto. De acordo com a perspetiva de John Thompson (inspirada em Ricouer), é a este "extenso processo de compreensão e autocompreensão" que se aplica o conceito de apropriação das mensagens mediáticas.

"Ao interpretar as formas simbólicas, os indivíduos incorporam-nas na compreensão que têm de si próprios e dos outros. Usam-nas como veículo de reflexão e autorreflexão, como uma base para pensar acerca de si próprios, acerca dos outros e acerca do mundo a que pertencem" (Thompson, 1995: 42).

O conceito de apropriação parece-nos, assim, adequado para uma abordagem histórica da dimensão da receção que diz respeito à rememoração interpretativa de conteúdos mediáticos num longo prazo, ou seja, aos seus significados enquanto textos. É a apropriação, enquanto significação prolongada na biografia dos indivíduos, que permite aos conteúdos manterem-se ativos na memória 50 anos após a sua receção e muito distantes do seu contexto original, enquanto outros textos que foram alvo de receção já entretanto deixaram de ter significado e apenas são evocáveis como referências nominais.

Pensamos, pois, que os dois níveis de análise - usos e apropriações - são valiosos para a pesquisa histórica sobre audiências, e que devem ser tomados como dimensões analíticas entrelaçadas quando se encara a receção como prática social. As circunstâncias em que o rádio foi instalado em casa, as formas como os membros da família se envolviam na escuta ou os programas específicos a que se deu significado, tudo isso pode ser abordado do ponto de vista da história oral.

Na verdade, todos os níveis de análise lidam com processos de significação, quer seja a interpretação de textos em si, quer sejam sentidos associados à própria atividade de escuta e ao ambiente social onde ela acontecia. Tratando-se de história oral, o que queremos enfatizar é a probabilidade de a memória ter diferentes articulações com os níveis da atividade das audiências que definimos como usos e como apropriação.

A nossa proposta para distinguir os usos dos media, visa captar as memórias não focadas na interpretação dos conteúdos mediáticos, mas as que se concentram no contexto de receção, com as suas ações e relações entre os membros da audiência. Assim, a memória dos usos dos media é uma memória especificamente acerca de 
significados da ação social, e não propriamente sobre significados dos conteúdos simbólicos dos textos mediáticos.

Estas dimensões da receção articulam-se de maneiras diferentes com questões de género e de dominação. Por um lado, a memória dos usos dos media refere-se a atores sociais concretos e às relações entre eles enquanto audiências. Por outro lado, as memórias ligadas à apropriação dos media incidem sobre objetos mediatizados histórias, personagens, eventos e pessoas públicas -, tendo por isso uma ressonância simbólica sobre tipos e representações sociais e sobre as suas posições, papéis e relações.

No presente texto partimos da divisão analítica exposta acima, mas na análise empírica baseada em entrevistas concentramo-nos na memória dos usos da rádio e da televisão.

\section{Dominação e hegemonia}

Interessando-nos articular um contexto histórico fortemente patriarcal com as práticas de receção hoje evocadas por audiências femininas, procuramos apoios teóricos capazes de iluminarem, ao mesmo tempo, uma estrutura assimétrica de poder e uma variedade de práticas não necessariamente homogéneas no seio dessa assimetria.

O conceito gramsciano de hegemonia designa uma liderança ideológica capaz de levar os grupos subordinados a interiorizar como seus o que na verdade são interesses do grupo hegemónico. Gramsci escreveu que "a constituição de um aparelho hegemónico, na medida em que cria um novo terreno ideológico, determina uma reforma da consciência e de meios de conhecimento" (Gramsci in Forgags, 1999: 192). A hegemonia implica, assim, a capacidade de um grupo dominante para guiar os dominados sem que se trate simplesmente de impor ou de iludir, mas sim de produzir consentimento (idem: 197). Temos um quadro hegemónico quando a ascendência de um grupo sobre outros é vista como legítima por todos. Os modos de consciência (no sentido de cognição e não de consciencialização) são mobilizados de forma que os grupos dominados encarem como normal uma dada relação de subordinação.

Retomando o conceito, Raymond Williams sublinhou uma visão da hegemonia enquanto processo histórico nunca totalmente fixo ou sistemático, mas composto por vários tipos de práticas sociais, que podem ser dominantes, residuais ou emergentes. A hegemonia existe "em formas ativas de experiência e consciência", diz Williams (1983: 145), mas algumas das práticas que ela acolhe podem ser intrinsecamente contraditórias, simultaneamente reafirmando e desafiando as relações dominantes. Por outro lado, tal como Gramsci não via a hegemonia ideológica como uma mera 
"superestrutura" determinada pelas relações sociais e económicas, também Williams reafirma que a transformação nas instituições ou nas relações sociais não causa necessariamente, e por si só, mudanças nas formas hegemónicas de experiência e consciência. A hegemonia pode perdurar para além da alteração das condições estruturais que a criaram.

Uma outra conceção, porém, rejeita a ideia de consentimento dos subordinados e vislumbra um poder de tipo simbólico que vai para além do campo ideológico. É o caso da abordagem de Pierre Bourdieu à dominação masculina.

Se o conceito de hegemonia é do foro ideológico, já Bourdieu opera uma deslocação conceptual que alarga a análise para além do campo da cognição dos atores subordinados (a consciência das mulheres supostamente invadida pelas ideias naturalizadas do poder masculino) e a transporta para o reino da "ordem das coisas", dos "princípios de visão e divisão" (de um mundo estruturalmente sexuado) que se tornam "disposições práticas" incorporadas nos atores sociais (Bourdieu, 1999: 7-8) e lhes limitam as possibilidades de pensamento e de ação. A “ordem simbólica” de que fala Bourdieu é a ordem androcêntrica, uma ordem de "oposições fundadoras" entre os sexos que "se impõem a cada agente como transcendentes" (1999: 29) e que se apresentam como "um sistema de exigências" (idem: 43) em que, por exemplo, o sentido de honra ou de estigma são inescapáveis porque corporalmente interiorizados.

Enquanto Gramsci considera (1999: 194) que a hegemonia ideológica é fundamental para se manter uma estrutura social assimétrica e relações de dominação, Bourdieu sustenta (1999: 34-36) que as raízes da dominação residem nas condições sociais de produção das disposições e que nem sequer a consciencialização dos subordinados é suficiente para a mudança, dado que a subordinação se funda em razões profundamente obscuras para si mesmas, pois estão acumuladas nos corpos e exprimem-se nas manifestações com que este foge ao controlo da vontade dos próprios atores (vergonha, retração, repulsa).

Mais do que uma ideologia que toma conta das mentes dos subordinados, o principal mecanismo reprodutor da dominação, segundo Bourdieu (1999: 36), é a assunção pelos subordinados de categorias de apreensão e de ação que são construídas do ponto de vista dos dominantes, e que os próprios dominados aplicam, fazendo-as parecer inteiramente naturais precisamente porque não são apenas atitudes do foro cognitivo.

Uma das raízes da dominação masculina reside na assimetria de posições que os homens (como sujeitos) e as mulheres (como objetos) ocupam na economia das trocas simbólicas. Num regime patriarcal, o feminino é o "ser-percebido" (Bourdieu, 1999: 
54), cujo estatuto depende do olhar masculino e em última análise se destina à acumulação de capital simbólico dos homens através do casamento. As mulheres são encarregues da valorização e reprodução simbólica no seio da família, através da gestão daquilo que nesta se relaciona com a apresentação e a aparência perante outros (Bourdieu, 1999: 85).

Este e outros mecanismos estruturantes é que permitiram que as relações patriarcais se reproduzam apesar das mudanças, podendo a subordinação feminina, como diz Bourdieu, exprimir-se por vezes na exclusão do trabalho assalariado e noutras na sua inclusão. Também o lazer, o trabalho doméstico ou o uso de espaços públicos - e as práticas associadas aos media que aí estão presentes com frequência - podem ser marcadas por sistemas de disposições incorporadas em termos de género. Portanto, também quanto à introdução da rádio e da televisão no quotidiano interessa apreender que transformações se operam e que homologias se reproduzem.

Uma das distinções entre os conceitos de hegemonia e de ordem simbólica é no que toca às possibilidades de transformação. Um campo hegemónico, por se considerar que alberga incoerências no exercício de dominação, admite que os grupos subordinados encontrem práticas de autonomia e resistência, vislumbrando assim fissuras de natureza cultural com que os atores sociais podem abrir caminho a transformações mais amplas.

Encarar as diferentes dimensões da receção mediática num contexto patriarcal como o do Estado Novo, permite-nos pensar na hipótese de a hegemonia ter apresentado distintas feições e de as mulheres terem deparado com espaços heterogéneos de dominação, resistência ou autonomia. Nesta hipótese, seria possível pensar algumas práticas da receção mediática como reforçando a submissão feminina, ao mesmo tempo que outras contribuiriam para atenuar ou subverter a dominação masculina.

A ideia de ordem simbólica é distinta da de hegemonia no sentido em que convida a ver para além das mudanças sociais e a perscrutar homologias estruturais que se podem inscrever em "constantes ocultas" (Bourdieu, 1999: 47) de um sistema de dominação persistente através das suas transformações.

\section{Método biográfico}

Não abundam as fontes sobre antigas práticas de receção mediática, sobretudo fora dos grupos privilegiados que costumam documentar as suas visões sobre uma dada época. De uma forma geral, a história oral tem servido quer as tentativas de incluir no registo histórico as experiências e as perspetivas de grupos que de outra forma ficariam 
escondidos da história, quer as pesquisas que visam apreender aspetos pouco acessíveis por outros meios, como o quotidiano doméstico (Perks e Thomson, 2008: ix).

A receção mediática está entre esses aspetos do passado que, além de pouco acessíveis, tendem também a não ser abordadas diretamente nas memórias orais das audiências. Razão pela qual a pesquisa histórica neste campo tem necessitado de uma indagação mais ampla, "olhando para as práticas sociais em torno dos media" (Bird, 2008: 96) em vez de procurar relatos diretos sobre a receção.

A história oral não tem como finalidade reconstituir as vidas dos entrevistados e interpretá-las como objeto de estudo em si, mas sim identificar processos e acontecimentos (Denzin, 1989: 41-42). Pode, porém, usar entrevistas biográficas como técnica de recolha, o que se justifica no caso de uma pesquisa histórica sobre receção pela necessidade de situar e articular os diversos relatos acerca dos media (audição da rádio, chegada da televisão, memórias de receção coletiva), com as várias fases da vida das audiências (infância, juventude, trabalho, matrimónio - nos planos doméstico e 'público') e as correspondentes fases históricas (quanto às circunstâncias políticas e às caraterísticas dos media). Este trabalho de contextualização é fundamental para se compreender os processos de receção e pensamos que ele só é possível se baseado em entrevistas biográficas, uma vez que só elas fornecem à pesquisa material passível de entrelaçar a memória pessoal com a dinâmica histórica.

Neste caso, designamos por entrevistas biográficas uma metodologia, já utilizada noutras pesquisas de história oral sobre audiências (Bourdon, 2003), que combina várias entrevistas semiestruturadas, a primeira das quais procura reconstituir a "história de vida" do participante, e as entrevistas posteriores abordam as várias fases de vida em busca de memórias mediáticas, que frequentemente se encontram ancoradas a situações familiares ('os primeiros anos de casada'), profissionais ('quando recebi o primeiro ordenado') ou a outras experiências pessoais.

É claro que a história oral requer cautelas de verificação e cruzamento com fontes externas e coevas, mas permite aquilo que será a principal vantagem desta metodologia: dar acesso, não apenas aos acontecimentos, mas sobretudo aos significados que os eventos tiveram (e têm) para as pessoas que neles participaram. Ou seja, a recolha oral não faculta apenas informação sobre o que as pessoas fizeram, mas também discursos sobre essas ações, revelando processos de subjetividade e reflexividade dificilmente acessíveis através de outros métodos (Portelli, 2008).

Neste texto usamos de forma exploratória material recolhido em entrevistas biográficas feitas com cinco operárias da Covilhã, que fazem parte de um conjunto mais alargado 
de entrevistas com mulheres de duas gerações: a das nascidas antes de 1939 (início da II Guerra Mundial) e a das nascidas entre o fim da guerra e o início das emissões de televisão em Portugal (1945-1957). A globalidade das entrevistas foi recolhida entre setembro de 2012 e agosto de 2013, a partir de contactos desenvolvidos em associações recreativas e de apoio à terceira idade na Covilhã e em Lisboa (com vista a comparar contextos territoriais distintos). A seleção das entrevistadas foi feita de acordo com a classe social de origem ('classe popular' e 'classe média') e com a referida estratificação geracional (visando observar a entrada de novos media em diferentes fases de vida).

No trabalho de campo, foram realizadas duas entrevistas a cada mulher. A primeira iniciada com um relato autobiográfico livre, seguido de uma inquirição mais detalhada das várias fases da vida, focada em tópicos como o espaço doméstico, as relações familiares, o trabalho e os espaços públicos. A segunda entrevista seguiu um guião semiestruturado em torno dos objetivos da nossa pesquisa, inserindo nas fases de vida questões relacionadas com receção e género.

A partir das entrevistas transcritas na íntegra tentou-se compreender as "histórias de vida", no sentido de "vida vivida" (Rosenthal, 2006: 3), ou seja, olhando os investigadores para os dados biográficos de modo a interpretar as experiências vividas numa sequência diacrónica. A importância da reconstituição de "histórias de vida" (life histories), enquanto "tentativas de reconstruir vidas baseadas em entrevistas e conversações" (Denzin, 1989: 42), reside na já referida relevância para a compreensão sequencial e contextualizada das práticas de receção. Não se trata, porém, de histórias de vida como género (life-stories) nem como técnica de recolha, na medida em que as narrativas não foram estritamente guiadas pela iniciativa das biografadas segundo os tópicos por elas considerados mais significativos.

A valia das entrevistas biográficas é reforçada quando se aborda um mesmo território e período histórico, tentando entender as práticas culturais coletivas de uma comunidade, de modo a compreender o lugar e o sentido que os media foram adquirindo no seu seio. Nesse sentido, fez-se uma análise simultaneamente diacrónica e sincrónica das memórias de usos e apropriações da rádio e da televisão, procurandose perceber as questões de género na gradual introdução de práticas de receção ao longo das vidas biografadas, mas também a articulação entre as várias dimensões e as várias biografias num mesmo corte temporal. Pontualmente, ensaiamos também alguns aspetos de análise do discurso, dentro do paradigma que examina "o papel do discurso na reprodução da dominação e da desigualdade" (Van Dijk, 1993: 253). Aqui, a abordagem prende-se com alguns modos "socio-semânticos" através dos quais os atores sociais são representados no discurso (Van Leeuwen, 1997). 


\section{Operárias da Covilhã e usos dos media}

O modelo de mulher 'domesticada', que o Estado Novo queria exclusivamente dedicada à casa e à família, era difícil de concretizar na Covilhã, núcleo fabril de lanifícios fortemente polarizado entre uma pequena elite de industriais abastados e milhares de ‘colarinhos-azuis' vivendo na miséria. No Portugal da década de 1930, o salário de um homem cobria apenas $72 \%$ das necessidades alimentares de uma família modesta (Barbosa, in Rosas, 1994: 94-95). Na Covilhã, o trabalho fabril não era complementado com agricultura de subsistência, pelo que todos os membros da família deviam contribuir com o seu salário, incluindo as crianças, na idade o mais precoce possível. A mulher apenas podia deixar de trabalhar temporariamente, e todos os salários da casa lhe eram entregues para que ela os gerisse.

O trabalho assalariado feminino coexistia quer com a retórica corporativa do regime acerca da família, que a sancionava como corpo coeso de membros desiguais, quer com a submissão das mulheres a apertados mecanismos de controlo social, em que a moral sexual e a vigilância sobre o corpo tinham um papel central. Não devemos, porém, vincular essa vigilância unicamente com as especificidades ideológicas do Estado Novo. As preocupações com a pureza e a honra das mulheres existem em muitas sociedades patriarcais (Ortner, 1996), onde a integridade dos membros da família, especialmente das mulheres, atesta a capacidade dos homens imporem disciplina dentro dos seus núcleos familiares.

Num Estado corporativista e tradicionalista como o Estado Novo, a correspondência entre integridade da família e integridade da nação era maior do que em outros sistemas políticos modernos, reforçando padrões de uma cultura patriarcal que já existia. Por exemplo, embora o culto da Virgem Maria já fosse parte importante da cultura católica em Portugal, foi durante o Estado Novo que Nossa Senhora de Fátima se tornou um ícone, com as celebrações anuais do santuário a serem transmitidas pela rádio (desde a década de 40) e pela televisão (a partir de 1958). É sintomático que a difusão deste evento seja dos episódios mais recordados entre as entrevistadas.

Em 1930, a taxa de analfabetismo entre as mulheres portuguesas era de 70\%. Foi nessa década que o Estado estabeleceu a primeira escola na Covilhã, a "escola central”. No contexto local, a frequência escolar parecia depender mais da classe do que do género, com as crianças de classe popular a frequentarem, no máximo, quatro anos de ensino. ${ }^{1}$

\footnotetext{
${ }^{1}$ Os dados de caraterização das operárias apresentados a partir daqui baseiam-se num conjunto mais alargado de entrevistas realizado na Covilhã (cerca de 25, das quais 16 de classe popular).
} 
Em geral, a entrada no mercado de trabalho acontecia imediatamente após o final da escola primária, aos 11 ou 12 anos de idade. As crianças começavam por transportar cortes de fazenda entre a fábrica e as mulheres que cerziam em casa. ${ }^{2}$ As raparigas eram iniciadas desde cedo no trabalho de cerzir, função que começavam a exercer em casa antes de entrarem na fábrica. Em 1934, o Estado reafirmou a proibição de trabalho para menores de 12 anos, mas a proibição era frequentemente desobedecida pelos empregadores. A forma como as crianças trabalhadoras se escondiam dos inspetores de trabalho é uma recordação corrente da infância das entrevistadas.

Também eram frequentemente desrespeitadas a duração da jornada de oito horas e a interdição de trabalho noturno para as mulheres. Era corrente as fábricas de lanifícios funcionarem continuamente, em três turnos diários. As mulheres geralmente trabalhavam nos turnos da manhã (das 6h30 às 15h) ou da tarde (das 15h às 23h30). Frequentemente, acumulavam o turno da fábrica com um segundo trabalho, em regra na limpeza de casas e escritórios. Era costume, até à adolescência, as raparigas acompanharem as mães nos trabalhos de limpeza e ajudarem-nas até à idade do casamento, continuando depois esse trabalho por sua conta. Nas décadas de 1950 e 1960 também se tornou uma segunda fonte de rendimento a venda de bolos e pastéis que se cozinhava a partir de casa.

À noite, depois de terminado o trabalho doméstico - inteiramente a cargo dos elementos femininos da família -, as cerzideiras e metedeiras de fios continuavam a trabalhar nos cortes que levavam da fábrica para casa. Esta entrada precoce no trabalho, tanto em casa como fora dela, reflete-se em narrativas biográficas onde o lazer está quase ausente.

Conceber os media como dispositivos usados pelas 'donas de casa' para preencherem tempos livres, que elas muitas vezes não têm, é algo que já foi desmistificado e que é contrariado também pela nossa pesquisa. Entre as operárias da Covilhã algumas das memórias mais antigas do uso da rádio exprimem um contexto de receção condicionado pelos papéis de género dentro do lar.

O excerto seguinte rememora uma certa rotina doméstica no núcleo familiar de Maria (nascida em 1935), no período em que ela tinha entre 12 e 15 anos e cerzia cortes de

\footnotetext{
${ }^{2} \mathrm{O}$ trabalho de cerzideira era uma especialização feminina dentro da divisão sexual do trabalho que vigorava no setor laneiro, onde as funções com salários maiores e mais prestígio eram masculinas, com destaque para a tecelagem. Os trabalhos reservados à mulher eram os relacionados com a preparação do fio (penteação, fiação, a urdideira) e, com os acabamentos da fazenda, como o trabalho de cerzideira ou metedeira de fios, que consistia em localizar defeitos e reparar manualmente os tecidos.
} 
fazenda em casa, trabalho que acumulava com o da fábrica, para minorar a insuficiência dos rendimentos familiares. ${ }^{3}$

Entrevistadora.- E ao sábado? Como era? Quando dava o Serão para Trabalhadores. 4 Era a que horas?

Maria - Oh, era à noite, depois de jantar. Depois do noticiário. Ah, a gente, quer dizer... pronto, o meu trabalho como era de estar em casa, não é, eu estava a trabalhar e a ouvir... Ah, claro a minha madrasta e as minhas irmãs, pronto, andava-se na lida da casa e sempre a ouvir o Serão para Trabalhadores.

E.- E o seu pai?

M.- O meu pai também. Bem, o meu pai, claro, o meu pai estava sossegadinho a ouvir. Ah... quando era no inverno, pronto, aquilo naquele tempo era as braseiras, não é? As pessoas sentavam-se à braseira a ouvir, pronto, era assim.

[Maria, nascida 1935]

Maria evoca aqui o interior da casa de uma família operária, nos anos do pós-guerra (1947-1950).5 A casa, sem eletricidade nem água canalizada, tinha uma cozinha com fogão a lenha e uma sala com mesa, cadeiras, floreiras, um guarda-louça, e o rádio, "grande, com botões de madeira”, ficava numa mesinha pequena.

Nestas noites de sábado no inverno, a rádio surge no registo a que Bourdon (2003) chama wallpaper memories ("pano de fundo"), uma memória de práticas instaladas e repetidas, memória típica daquilo que designámos por usos dos media, ou seja, uma narrativa cujo primeiro plano é ocupado pelos atores sociais no desempenho dos seus papéis e nas suas relações enquanto dão uso à rádio, e não uma evocação dominada pela atividade interpretiva dos conteúdos simbólicos dos media.

A evocação que a entrevistada faz hoje daqueles sábados à noite mostra-no-los como momentos de notável saliência dos papéis de género, mas no seu discurso estes não são abordados em termos de desigualdade. Uma análise da forma como a cena é elaborada discursivamente pode dar-nos mais pistas.

Maria começa por situar esta memória no quadro da família, de um coletivo reunido ao serão, em casa (depois do noticiário, “a gente”...), mas quando tenta descrever os usos

\footnotetext{
3 Os nomes com que se identifica as entrevistadas são pseudónimos.

4 "Serão Recriativo para Trabalhadores" foi um programa transmitido pela Emissora Nacional, em colaboração com a Fundação Nacional para a Alegria no Trabalho, a partir de 1941.

5 A Covilhã da década de 1940 incluiu fortes tensões sociais, exacerbadas pelo agravamento da carestia operária durante a guerra e que despoletaram a primeira greve que abalou o regime do Estado Novo, em 1941 (descrita por Ferreira de Castro no romance "A Lã e a Neve").
} 
da rádio vê-se obrigada a ligá-los a outras práticas da esfera doméstica, e o que acontece é que o discurso separa e distingue imediatamente três tipos de atores: ela própria, rapariguinha a cerzir fazendas para a fábrica; as mulheres da família, atarefadas no trabalho doméstico; e o pai, exclusivamente escutando rádio. Este movimento semântico liga-se ao discurso hegemónico acerca da família no Estado Novo, em que os indivíduos, dentro da sua condição fundamental de membros do coletivo, se encaram como naturalmente desiguais (e não simplesmente diferentes) através do género, que os dissocia nas práticas de trabalho e lazer domésticos com as quais o rádio se vem articular.

Isso mesmo é patente na escolha de pronomes indefinidos nas frases "andava-se na lida da casa" e "as pessoas sentavam-se à braseira a ouvir". A estrutura das atividades domésticas atribui papéis diferentes a cada elemento da família, de acordo com o seu sexo: ao pai o de escutar rádio descansando; à madrasta e às irmãs o de escutar rádio trabalhando. Porém, o discurso de Maria sobre a divisão do trabalho e do lazer não só evoca esses papéis de forma naturalizada, como a linguagem recorre a modos de “indeterminação" dos atores, processo através do qual estes são anonimizados, tratando-se as suas identidades como irrelevantes (Van Leeuwen, 1997: 199). Tal indeterminação parece-nos uma modalidade do discurso hegemónico na medida em que escamoteia as desigualdades e assim se insere nos processos de construção da normalidade da subordinação feminina, apresentando um padrão 'genderizado' como se os papéis sociais incumbissem indiferentemente a qualquer um. O seu caráter hegemónico evidencia-se ao ser reproduzido ativamente na própria memória e no discurso femininos.

A exiguidade das habitações e o clima quente da Covilhã durante o verão fazia as pessoas saírem para a rua. Os vizinhos juntavam-se à porta das casas e, por vezes, faziam bailes. Os bailes eram muito apreciados pelas jovens como raras oportunidades de socialização para além da soleira da porta, especialmente quando eram autorizadas a ir a outros bairros ou a centros recreativos. Em todo o caso, só podiam ir se acompanhadas por irmãos, irmãs, mães ou vizinhas. A frequência destes bailes era geralmente interrompida assim que as mulheres se casavam ou se comprometiam com um namorado.

Aos 15 anos (1950), Maria conhece o futuro marido, precisamente num baile, e começa a namorar. Mas o namoro acaba por ditar o fim imediato das suas idas aos bailes: «Foi logo quando a gente começou a namorar, que ele me disse: Se me fizeres a vontade, não vais ao baile, não vais mais ao baile.» Também na biografia de outra entrevistada, Ilda (nascida em 1945), sobressaem vários episódios ligados ao lazer fora de casa, neles 
avultando modalidades e protagonistas diversos no exercício do controlo sobre a ação e o corpo femininos:

«Em qualquer cantinho se fazia um baile. Além onde eu morei também se faziam bailes, e então o meu irmão se me visse lá assim à porta... Eu tinha um medo dele que me pelava! Era dele e da minha irmã mais velha.»

A frequência de espaços públicos por raparigas e mulheres era, pois, rigorosamente vigiada por atores sociais concretos - irmãos e irmãs, pais e namorados, parentes e vizinhas -, mas também se inseria numa teia de normas e interditos impessoais, manifestações particulares das estruturas de dominação masculina que se impunham na própria orgânica do baile. Aida (nascida em 1947) descreve um tipo de bailes que decorria segundo uma lógica de arrematação:

\section{E.- E como é que eram os bailes? Como é que funcionavam?}

A.- (...) Fazia-se lá os bailes e depois arrematava-se coisas, um ramito de flores, ou um pacote de bolachas. E era assim: a pessoa só podia dançar se um rapaz ficasse com aquilo; dançava com quem ia buscar e não podia mais ninguém dançar. (...) aquilo era arrematado. Por exemplo, era esta chávena, um rapaz ficava com ela. Ia buscar uma rapariga (...) [A rapariga] tinha que aceitar e depois só dançava com mais alguém se ele deixasse.

[Aida, nascida 1947]

A par de uma "economia económica” marcada pela magreza operária, funcionava uma vigorosa "economia simbólica" (Bourdieu, 2001) e nela verificamos de que modo objetos económicos (com um preço, como o pacote de bolachas) podem cumprir uma função proeminente de bens simbólicos, mas vemos sobretudo como coisas (bens materiais) e raparigas solteiras integram um mesmo sistema simbólico na qualidade de objetos, onde os sujeitos são os homens.

Depois do casamento, a sociabilidade quotidiana fora da esfera familiar, no caso das operárias entrevistadas, estava geralmente restringida à fábrica, à missa e ao mercado onde iam comprar comida. A gestão da "féria" (salário semanal dos operários, praticado na época) do conjunto dos membros da família era-lhes entregue praticamente sem restrições explícitas.

E.- Quando foi para a fábrica já só eram a senhora e esse irmão que viviam em casa dos pais.

I.- Sim. Pois, em casa dos meus pais, era. Era. E eu pronto, gostava de ganhar assim uma feriazinha para dar à minha mãe. 
(..)

E.- Depois, quando a senhora se casou, também era a senhora que recebia a féria do seu marido?

I.- Sim. Quando eu me casei tinha que me dar a féria. Ficava com tanto para o bolso, está a perceber? Antigamente era assim. Que o meu marido fumava, pronto. E ele... dava-me, pronto, o que me havia de dar e depois ele ficava com xis para o resto.

[Ilda, nascida 1945]

Dentro desta economia doméstica, a mulher detém uma esfera de autonomia que tem duas implicações relevantes, exemplificadas também pela biografia de Maria. Por um lado, essa autonomia abrigava um contraste entre a garantia de uma (pequena) verba para o lazer do marido fora de casa e a ausência de dinheiro para uso pessoal da mulher.

M.- Ele dava-me a féria, eu tinha que cuidar de tudo. O dinheiro com que ele ficava era para as paródias dele, pronto.

E.- E a senhora?

M.- Eu? Eu não tinha paródias [ri]. Olha, paródias... Não. Não.”

[Maria, nascida 1935]

Por outro lado, a autonomia na gestão da féria significava que era da mulher o fardo de garantir o quotidiano sustentável da família, podendo-lhe ser imputadas as faltas e uma suposta incapacidade para orientar a casa.

Se a gente tirasse, por exemplo, dez escudos [da féria] e os pusesse de parte, a gente ficava radiantes. Para que se houvesse alguma coisa de repente, a gente ter assim qualquer coisinha. Eu apesar que era muito novita quando casei, mas tinha esse pensar assim. Eu conseguia. Às vezes não era porque eu os lá pudesse pôr, mas fazia mil e um sacrifícios para pôr. [Maria, nascida 1935]

Ao sistema de vigilâncias restritivas sobre a sociabilidade da mulher acrescentava-se, portanto, a improbabilidade de dispor de dinheiro próprio e, sobretudo, um constrangimento moral para não fazer despesas consigo mesma.

De qualquer modo, o facto de esta esfera de consumo, que podemos caraterizar como de autonomia constrangida, ser eminentemente feminina proporcionava algumas brechas que mulheres e raparigas iam usando dentro de um apertado sistema de 
normas e em que sobressaem os aspetos ligados à aparência, num jogo entre o serem vistas e o não se darem a ver, que pode igualmente ser interpretado como parte de uma economia simbólica, orientada para a acumulação pelas famílias do capital simbólico 'honra'.

Antigamente não se podia ir à missa sem um véu. (...) Eu tinha um muito bonito, assim cinzento e preto, que os véus era tudo preto. Antigamente não se entrava para a igreja sem o véu. Depois houve uma altura que as pessoas até tinham vaidade a ver quem é que levava o véu mais bonito. $\mathrm{E}$ a minha mãe comprou-me assim um grande, muito bonito... Se fosse agora não punha [ri], eu não queria ter nada na cabeça. (...) Pronto, usavam-se esses véus e eram essas tais mulheres que iam à Espanha, compravam, chamavam-lhe as madrilenes. (...). Vendiam assim muita coisa. Até garrafas de whiskey [sussurra]... por isso é que lhe chamavam o contrabando. Se a polícia as apanhasse, pagavam uma multa que não imagina. Elas andavam à chucha calada assim pelas ruas a vender essas coisas. O Tokalon era muito visto... eu ainda usei esse creme. E era uns frasquinhos de perfume que era o Tabu. [Ilda, nascida 1945]

É neste esfera de consumo, em que a economia económica se entrelaça com a economia simbólica, que gradualmente vão surgir as várias tecnologias domésticas, incluindo a "telefonia" e a televisão e todo o leque de publicidade comercial dirigida ao público feminino. Trata-se, como vimos, de uma esfera de ação onde a mulher casada detém uma autonomia que a dissuade de fazer gastos para seu benefício pessoal, mas que a autoriza a tomar decisões que possam ser consideradas em prol da casa e da família.

E.- Já tinham aparelhos elétricos na primeira casa?

A.- Na primeira não, na segunda já tinha frigorífico, depois tive a máquina de lavar roupa.

(..)

E.- E rádio e televisão?

A.- Não. Depois é que comprei. Uma vez andava a varrer a casa, a casa era muito... doía-me as costas, pousei a vassoura, saí de casa, fui buscar um aspirador [ri]. (...) E a televisão também foi assim.

E.- Mas já na casa nova? Já nesta onde está vive hoje?

A.- Não, não. Na segunda. A televisão, a minha filha, coitadinha, dizia... pronto, era pequenina, depois queria ver televisão. Um dia também saí de casa, disse assim: Eu vou comprar uma televisão. Quando o meu homem chegou a casa, já lá tinha a televisão [ri]. 
[Aida, nascida 1947]

Maria, que aos 15 anos (1950) acatou o pedido do namorado para nunca mais ir a bailes, aos 23 anos comprou com a sogra um rádio para oferecer ao marido; e em 1963 decidiu, por sua iniciativa, comprar uma televisão, que já não foi apresentada como uma prenda para o marido, mas que veio inserir-se no mesmo sistema doméstico de disposições práticas que lhe estava incorporado desde os tempos do escutar rádio trabalhando ao serão em casa do pai. Depois de casada, a aquisição de televisor também corresponde às funções de representação simbólica que lhe competem no seu próprio núcleo familiar, onde aquele funciona como capital simbólico perante vizinhos e parentes.

Quando comprei a televisão, era a mesma coisa. Enchia-se uma casa com os vizinhos a verem a televisão e eu estava a trabalhar. Eu ouvia. Eu não via, eu ouvia. (...) porque naquele tempo nem qualquer pessoa comprava televisão, e então as pessoas que não tinham... E então no prédio onde eu morava havia muitos moços e, eles coitados, gostavam de ver, e então iam para a minha casa ver, à noite. Andavam na escola, depois à noite iam para a minha casa. Eu estava a trabalhar... [Maria, nascida 1935]

Porém, esta audiência atarefada não era única forma de as mulheres usarem os novos media eletrónicos da época. A rádio já incluíra uma espécie de audição 'comunitária' com os sons a propagarem-se através das janelas, pelas ruas e a tornarem-se envolventes, podendo também acontecerem algumas ocasiões de escuta em casa de parentes. Mas a televisão alargou claramente esta modalidade de uso coletivo em espaços domésticos de familiares e vizinhos.

Foi nessa altura [idade de 15 anos] que as televisões começaram a aparecer. E então, no bairro acho que a primeira pessoa a ter televisão foi a minha irmã. (...) À noite íamos todos lá para casa da minha irmã, tudo sentado no chão. Quem se podia sentar, sentava-se, não é, porque... as cadeiras também não eram muitas, e a casa também era pequenina, que a minha irmã morava também no bairro. (...) $\mathrm{E}$ então nós íamos todos para lá ver... A minha irmã Augusta - ainda não tinha -, era a minha mãe e o meu pai, e era a garotada toda, iam as vizinhas e tudo para ali ver a televisão. (...) Nós tínhamos que ver os programas todos, enquanto a gente ali estivesse. [Ilda, nascida 1945]

Nesta modalidade de uso da televisão há vários aspetos significativos. Em primeiro lugar, a deslocação para casa de parentes ou vizinhos não se dava acoplada a quaisquer outras práticas, mas era feita propositada e assumidamente para ver televisão. Em segundo lugar, a televisão parece ter proporcionado às operárias da Covilhã na década 
de 60, a criação de um tempo regular de lazer, umas horas de descanso e entretenimento que, de forma inédita, se tornam rotineiras ao serão, algo que até aí era uma prerrogativa exclusivamente masculina. Por fim, a instituição deste ritual de visionamento coletivo parece ter envolvido, sobretudo, mulheres e crianças, a maior parte dos homens mantendo os seus espaços coletivos públicos. Mas este não foi um tempo de lazer definitivamente adquirido pelas mulheres, porque a aquisição do seu próprio televisor veio de novo combinar a visualização com o desempenho das tarefas domésticas.

Um ponto relevante para a nossa análise consiste precisamente em notar a aparente permissividade com que aquela estrutura de dominação masculina que vimos ser fortemente constrangedora para a mulher acolheu desde o início a televisão e as práticas que com ela se articularam. Em contraste com os interditos do acesso feminino a espaços públicos, estão notavelmente menos presentes as restrições de acesso à esfera pública mediada através da rádio ou da televisão, e é admitido um leque de usos possíveis dos media por parte das mulheres.

Mas, na verdade, estes usos femininos dos novos media, a sós ou em grupo, na própria casa ou em casa de outras mulheres, não apenas se mantiveram no interior das normas estruturadas pela ordem masculina (e quanto aos conteúdos simbólicos, esta podia confiar na ideologia do Estado Novo e no seu sistema censório), como também a rádio e a televisão podem ser vistas como aliados no projeto de 'domesticação' da mulher, oferecendo-lhe motivos para se manter voluntariamente na esfera doméstica após o tempo passado na fábrica. A associação entre televisão e frequência feminina de espaços públicos é invulgar, tornando-se memorável nas biografias.

E.- [Lembra-se] Assim algum acontecimento importante, que as pessoas ficaram todas a ver na televisão?

A.- (...) Lembro-me de ver o Papa quando veio a Fátima, o... Como é que se chamava? João Paulo I. Quando veio a Fátima, as tabernas eram das mulheres nesse dia. Estava tudo na taberna. Os homens... Verdade! Tinha lá um vizinho, que era... eu sei lá, enquanto não acabou, ninguém saiu. O meu vizinho chegou lá e disse assim:

- Ó Rita, então mas hoje venho-te eu chamar à taberna?

As mulheres, estava tudo na taberna, porque, quer dizer, pouca gente tinha televisão, e foi um acontecimento, pronto, que eu me lembrasse nunca tinha acontecido, não é? Ele veio a Fátima e a gente foi todas para a taberna. Eu era 
miúda, e lembro-me de ir para a taberna ver o Papa. Toda a manhã. Estivemos lá toda a manhã até acabar as cerimónias de Fátima.

[Aida, nascida 1947]

O evento mediático referido neste trecho ${ }^{6}$ não é o facto central na memória da entrevistada, cujo discurso atribui o significado proeminente à ação protagonizada pelos atores sociais em articulação com determinado uso da televisão. Este exemplo reafirma que uma parte importante da história e da memória da receção mediática tem a ver com o envolvimento dos sujeitos em práticas e relações significativas entre si, e não apenas com encontros entre "textos" e "leitores" dominados pela atividade interpretativa das audiências.

O enquadramento principal da narrativa rememorada não nomeia atores específicos, mas antes os categoriza através da "classificação" (mulheres e homens), modo sociosemântico que identifica as classes de atores sociais tidas como mais relevantes num dado quadro histórico e cultural (Van Leeuwen, 1997: 202). Em contraste com o caso antes apontado de indeterminação dos atores no contexto doméstico (que indicava o género como impercetível), esta irrupção de mulheres e homens como classes de atores no discurso sugere a consciência de uma condição de género, precisamente porque se põe em causa o quadro hegemónico que definia uma genderização clara dos espaços públicos. A nomeação de alguns atores surge posteriormente na narrativa, especificando indivíduos cuja relevância reside, também, na inversão dos papéis sociais habituais de marido e mulher.

O episódio é rememorado devido ao caráter excecional do uso da televisão. Aida não o apresenta, porém, como algo que converta um determinado espaço em território permeável para ambos os sexos, mas sim como uma substituição ocasional de um género pelo outro, como se fosse um ritual que, ao invés de diluir linhas de separação, o que faz é vincar o sentido de diferença entre papéis masculinos e femininos e a sua inscrição em espaços próprios. Neste aspeto, a articulação dos usos com a apropriação do conteúdo simbólico é analiticamente relevante, pois a momentânea condescendência da presença das mulheres num local marcadamente masculino dá-se associada à visualização de um programa que acentua a demarcação de papéis sociais: as cerimónias religiosas marianas, um evento particular da religião católica, que constituía um dos núcleos ideológicos do regime político e do sistema patriarcal.

\footnotetext{
${ }^{6}$ Provavelmente, trata-se da transmissão das celebrações de Fátima num ano anterior ao da visita do Papa. A transmissão televisiva da visita de Paulo VI ocorreu nas cerimónias de Maio de 1967, e foi a única ocasião em que um Papa veio a Portugal durante as décadas de 1950 e 60. A alusão ao tempo de "miúda" e o facto de em 1967 a entrevistada trabalhar como criada de servir em Lisboa levam a crer que se trate de uma sobreposição dos dois eventos na sua memória.
} 
Portanto, esta atitude de especial e fugaz permissividade "territorial" para com as mulheres no interior da ordem masculina deverá algo ao facto de a religião ser interpretada como a principal fonte de valores morais que a mulher, como guardiã do lar e da família, estava compelida a seguir. Para mais, a Virgem Maria representava a harmonização de duas virtudes ideais, porém paradoxais, da feminilidade: a maternidade e a virgindade.

Apesar disso, e voltando aos usos da televisão, a alusão a que tal "nunca tinha acontecido" refere-se implicitamente à possibilidade, que mais tarde se abriu, de as mulheres passarem a frequentar espaços públicos anteriormente reservados aos homens. Esta possibilidade é aqui relacionada com a televisão, pelo que podemos admitir que a receção televisiva tenha sido, a posteriori, incorporada nalguns discursos femininos como uma prática que contribuiu para um uso menos rígido do espaço público em termos de géneros.

\section{Conclusão}

A teia de dados biográficos aqui expostos permite-nos ensaiar uma tentativa de compreender o que a introdução de novas práticas, ligadas a novos media, representou no meio operário da Covilhã, em termos de hegemonia ou de ordem masculina, ao longo do período do Estado Novo.

Os primeiros anos da televisão parecem ter inaugurado uma rotina diária de repouso e entretenimento para algumas mulheres, mas os dados exploratórios que obtivemos não indiciam um esboço de mudança cultural no qual começassem a emergir aspirações ao lazer por parte das mulheres entrevistadas.

Nesse processo, parece não ter havido abalos num campo hegemónico que continuou a produzir um senso comum, partilhado por mulheres e homens, com papéis de género bem demarcados e fortemente assimétricos. As práticas sociais reprodutoras dessa assimetria então associadas à rádio e à televisão, ainda hoje são evocadas, geralmente, de uma forma naturalizada.

Nas entrevistas biográficas analisadas, a criação de um tempo de lazer feminino, sobretudo em redor da televisão, esteve episodicamente ligada ao seu usufruto coletivo - com a parentela ou a vizinhança - em espaços domésticos bem determinados, e a aquisição de televisor próprio não significou de todo a instituição de um período quotidiano de lazer, só o proporcionando em fases da vida menos sobrecarregadas de trabalho doméstico e assalariado. 
Esta manutenção da ordem masculina não deixou de permitir espaços de autonomia, cujo principal exemplo era a gestão das finanças familiares. Mas as práticas levadas a cabo nesses espaços autónomos pelas mulheres entrevistadas - tomar a decisão de comprar um televisor; reservar o serão para ir a casa de irmãs ou vizinhas ver televisão; invadir as tabernas numa ocasião particular - talvez possam ser vistas como episódicos momentos de resistência perante as normas de género. Mas nunca parecem ter configurado práticas de subversão da ordem simbólica androcêntrica, com a sua estruturação do mundo, na qual os novos media se integram proporcionando apenas novas variantes da mesma dominação, reafirmando a mulher nos mesmos papéis e lugares tradicionais relativamente à esfera doméstica e aos espaços públicos.

\section{Referências bibliográficas}

Bird, Elisabeth (2008). Seeking the Historical Audience: Interdisciplinary Lessons in the Recovery of Media Practices. In B. Zelizer (ed.), Explorations in Communications and History. New York: Routledge, 90-106.

Bourdieu, Pierre (1999). A Dominação Masculina. Oeiras: Celta.

Bourdieu, Pierre (2001). Razões Práticas: Sobre a Teoria da Acção. Oeiras: Celta.

Bourdon, Jerôme (2003). Some Sense of Time: Remembering Television. History \& Memory, 15 (2), 5-35.

Denzin, Norman (1989). Interpretive Biography. Newbury Park: Sage.

Forgags, David (ed.) (1999). A Gramsci Reader: selected writings 1916-1935. Londres. Lawrence and Wishart.

Jensen, Klaus Bruhn (1993). The Past in the Future: Problems and Potentials of Historical Reception Studies. Journal of Communication, 43 (4), 20-28.

Ortner, Sherry (1996). Making Gender: The Politics of Erotics and Culture. Boston: Beacon Press.

Rosenthal, Gabrielle (2006). The Narrated Life Story: On the Interrelation Between Experience, Memory and Narration. In Narrative, Memory \& Knowledge: Representations, Aesthetics, Contexts. Huddersfield: University of Huddersfield, 1-16.

Rosas, Fernando (1994). História de Portugal. Sétimo volume: O Estado Novo (19261974). Dir. José Mattoso. Lisboa: Editorial Estampa.

Perks e Thomson (eds.) (2008). The Oral History Reader. Londres: Routledge.

Podber, Jacob (2007). The Electronic Front Porch: An oral history of the arrival of modern media in rural Appalachian and the Melungeon community. Macon: Mercer University Press.

Portelli, Alessandro (2008). What makes oral history different. In R. Perks \& A. Thomson (eds.), The Oral History Reader. Londres: Routledge, 32-42. 
Thompson, John B. (1995). The Media and Modernity: A Social Theory of the Media. Cambridge: Polity.

Van Dijk, Teun (1993). Principles of critical discourse analysis. Discourse \& Society, vol.4 (2), 249-283.

Van Leeuwen, Theo (1997). A representação dos actores sociais. In E. R. Pedro (org.), Análise Crítica do Discurso. Lisboa: Caminho, 169-222.

Williams, Raymond (1983). Keywords: A Vocabulary of Culture and Society. Londres: Fontana.

José Ricardo Carvalheiro é Mestre em Sociologia e Doutor em Ciências da Comunicação. No LabCom, integra a linha de investigação Media, Identidades e Cidadania e coordena o projeto de pesquisa "Recepção e Memória de Audiências Femininas no Estado Novo". Entre os seus interesses de investigação salientam-se, ainda, as relações entre os media, as migrações e as identidades culturais. Faz parte do Departamento de Comunicação e Artes da UBI, onde dirige a licenciatura em Ciências da Comunicação. Desde 2012, dirije a editora Livros LabCom.

Diana Gonçalves Tomás é bolseira de investigação no LabCom, no âmbito do projecto "Recepção e Memória de Audiências Femininas no Estado Novo". Tem uma licenciatura em Antropologia, pela Instituto Universitário de Lisboa (ISCTE-IUL), e um mestrado em Migrações, Inter-etnicidade e Transnacionalismo pela Universidade Nova de Lisboa.

Agradecimento:

Este trabalho é financiado pelo FEDER através do Programa Operacional Factores de Competitividade - COMPETE e por fundos nacionais através da FCT - Fundação para a Ciência e a Tecnologia no âmbito do projecto de investigação PTDC/CCI$\mathrm{COM} / 119014 / 2010$. 